\title{
BMJ Open Socioeconomic status and health-related quality of life among patients with prostate cancer 6 months after radical prostatectomy: a longitudinal analysis
}

\author{
Jens Klein, ${ }^{1}$ Kerstin Hofreuter-Gätgens, ${ }^{1}$ Daniel Lüdecke, ${ }^{1}$ Margit Fisch, ${ }^{2}$ \\ Markus Graefen, ${ }^{3}$ Olaf von dem Knesebeck ${ }^{1}$
}

To cite: Klein J, HofreuterGätgens K, Lüdecke D, et al. Socioeconomic status and health-related quality of life among patients with prostate cancer 6 months after radical prostatectomy: a longitudinal analysis. BMJ Open 2016;6: e010968. doi:10.1136/ bmjopen-2015-010968

- Prepublication history for this paper is available online. To view these files please visit the journal online (http://dx.doi.org/10.1136/ bmjopen-2015-010968).

Received 23 December 2015 Revised 1 March 2016 Accepted 21 March 2016

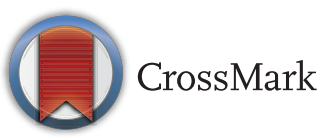

${ }^{1}$ Department of Medical Sociology, University Medical Center Hamburg-Eppendorf, Hamburg, Germany ${ }^{2}$ Department of Urology, University Medical Center Hamburg-Eppendorf, Hamburg, Germany ${ }^{3}$ Martini-Clinic, Prostate Cancer Center, University Medical Center Hamburg-Eppendorf, Hamburg, Germany

Correspondence to Dr Jens Klein; j.klein@uke.de

\section{ABSTRACT}

Objectives: To identify the associations between socioeconomic status (SES) and health-related quality of life (HRQOL) and the explanatory contribution of disease, patient and healthcare factors among patients with prostate cancer.

Design: Prospective cohort study.

Setting and participants: In all, 246 patients from 2 hospitals in Hamburg/Germany who underwent radical prostatectomy completed a questionnaire shortly before discharge from hospital and again 6 months later.

Outcome measures: HRQOL as assessed by the European Organisation for Research and Treatment of Cancer (EORTC) QLQ C-30 including global quality of life, 5 functional scales and 9 symptom scales/items. Generalised estimating equations were calculated to analyse longitudinal data.

Results: Lower SES measured by income, education and occupational status is significantly associated with lower HRQOL 6 months after treatment. This especially holds true for the functional scales. After introducing disease, patient and healthcare factors, associations remain significant in the majority of cases. The explanatory contribution of patient factors such as comorbidity or psychosocial characteristics and of healthcare factors is slightly stronger than that of disease factors.

Conclusions: We identified strong social inequalities in HRQOL among patients with prostate cancer 6 months after surgery, in Germany. The underlying causes could not be sufficiently identified, and further research regarding these associations and their explanatory factors is needed.

\section{INTRODUCTION}

Numerous studies have shown significant associations between socioeconomic status (SES) and morbidity as well as mortality. ${ }^{1-3}$ Even in modern welfare states, lower income, education and occupational position predict worse health outcomes in terms of a social

\section{Strengths and limitations of this study}

- To our knowledge, this is one of the first studies to systematically analyse the effects of different socioeconomic status indicators and various explanatory factors on multiple dimensions of health-related quality of life (HRQOL) 6 months after treatment of prostate cancer, especially in a European healthcare setting.

- The longitudinal design allows drawing conclusions about causalities.

- An established multidimensional instrument for HRQOL was used and a number of disease-related, patient-related and healthcare-related factors for explanation were considered.

- The selective study population and missing values limit the results.

gradient. ${ }^{4}$ Regarding prostate cancer, the prostate being one of the most prevalent cancer sites worldwide, social inequalities exist, particularly in survival, ${ }^{56}$ an outcome that is also known to be predicted by health-related quality of life (HRQOL). ${ }^{7} 8$ While HRQOL among patients with prostate cancer was investigated in numerous studies, ${ }^{9-12}$ research focused on the association between SES and HRQOL was conducted less frequently. ${ }^{13}$ As existing studies differ strongly in their methods (eg, measurement of HRQOL, observation time, sample characteristics, healthcare system), general conclusions are difficult to draw. A longitudinal US-American study has shown lower quality of life among patients with lower income 6 months after diagnosis but not lower education. ${ }^{14}$ At subsequent followups, the associations disappeared. Data from a cross-sectional Canadian study indicated strong relationships of favourable SES with better HRQOL outcomes. ${ }^{15}$ Dutch long-term prostate cancer survivors with low SES showed worse mental HRQOL 5-10 years after initial 
diagnosis. ${ }^{16}$ Further studies consist of samples limited to low-income men and analysed inequalities within the sample or drew comparisons with population controls. ${ }^{17-19}$ Two other studies found lower HRQOL among lower SES patients but differences diminished during the time after treatment. ${ }^{20}{ }^{21}$ However, these studies examined patients with mixed-site cancer and no explicit data for prostate cancer were given.

Furthermore, there is ongoing discussion about the underlying causes that lead to the social inequalities in health outcomes among patients with cancer. ${ }^{5}$ Explanatory factors are commonly separated into three groups: ${ }^{622} 23$ disease-related factors (tumour stage, biological characteristics), patient-related factors (comorbidity, health behaviour, psychosocial characteristics) and healthcare-related factors (treatment, screening uptake, medical expertise). Prior research among patients with prostate cancer found associations between lower SES and advanced stage at diagnosis, ${ }^{24}{ }^{25}$ severe comorbidity, ${ }^{26}{ }^{27}$ psychosocial conditions, ${ }^{28}$ and healthcare access and use, ${ }^{29}{ }^{30}$ but their impact on health outcomes remains unclear. Thus, there is not much known about the contribution of these factors to the explanation of social inequalities in HRQOL.

The present study aimed to analyse the association between SES and HRQOL among patients with prostate cancer 6 months after radical prostatectomy. Second, disease-related, patient-related and healthcare-related factors were included into the analyses to examine their impact on socioeconomic differences in HRQOL. So, we assume that patients with prostate cancer with a lower SES demonstrate poorer HRQOL 6 months after radical prostatectomy than do patients with higher SES and that inequalities persist due to a higher burden of disease, adverse psychosocial conditions and deprivation in access, use and quality of healthcare among patients with lower SES.

\section{METHODS}

Study design and sample

A prospective observational study was conducted. Baseline data were collected after treatment, shortly before discharge from hospital. Six months later, follow-up data were surveyed. Since the use of healthcare after acute treatment was a substantial outcome in this study, follow-up of 6 months was chosen to minimise recall bias. The process of aftercare such as rehabilitation has usually been completed by that period of time. The consecutive recruitment included patients from two acute care hospitals in Hamburg, Germany, after primary manifestation of prostate cancer. The two cooperative hospitals are certified by the German Cancer Society and are among the biggest prostate cancer centres in the country. Patients were excluded (1) if they were over 65 years of age (so as to include as many employees as possible); (2) if their health impairment was so serious that it hampered the filling out of the questionnaire; (3) if they presented with a seriously advanced stage of disease; or (4) further severe noncancer diseases; or (5) were seriously affected by mental stress; (6) had poor eyesight; (7) defective hearing or (8) insufficient knowledge of the German language. The exclusion criteria were assessed by the attending physicians, who were asked to estimate if participation was reasonable or not. At baseline, 296 patients were contacted, of whom 246 patients completed the written questionnaire on average 3 days after surgery (response rate: $83 \%$ ). Of these, 233 patients took part in the mail survey at follow-up 6 months later (response rate: 95\%). Data at baseline were surveyed between November 2013 and April 2014. All patients were treated based on the same standardised process and underwent radical prostatectomy (142 patients by open-surgical removal of the prostate and 104 by robot-assisted surgery). The study was conducted in agreement with the principles of the Declaration of Helsinki, received Institutional Ethics Committee approval (PV 4493) and strictly adhered to data safety regulations. Participants gave their written informed consent for the use of their data.

\section{Measures}

SES was assessed by net equivalent household income ( $€$ per month), taking into account the size of the household, highest educational level $(9, \quad 10$ or 12-13 years of schooling, according to the German educational system) and occupational position via an autonomy scale, resulting in four hierarchic groups. ${ }^{31}$ As disease-related factors, tumour stage according to the Union for International Cancer Control (UICC), Gleason grade and surgical margin status were included by gathering information from the medical reports provided by the hospitals at baseline. Patient-related factors (at baseline) were comorbidity based on patient's report (number of chronic diseases including the categories 0 / $1 / \geq 2$ ), cancer-specific coping strategies assessed by the Mini-Mental Adjustment to Cancer (Mini-MAC) ${ }^{32}$ and social support measured by the eight-item short version of the Illness-specific Social Support Scale (ISSS, German Version). ${ }^{33}$ The two subscales of the ISSS, positive support and detrimental interaction, were validated in Germany among patients with cancer with different tumour sites. Analyses showed acceptable-to-good psychometric properties (Cronbach's $\alpha=0.88$ for the subscale positive support and 0.68 for the subscale detrimental interaction). The Mini-MAC aims to evaluate patients' cognitive and behavioural responses to cancer as well as the ensuing reactions, consisting of patients' thoughts and behaviours, to reduce the threat of cancer. The subscales of the instrument provide five different coping strategies, defined as fatalism (ie, the tendency to have a resigned and fatalistic attitude towards the illness), fighting spirit (ie, the tendency to confront and actively face the illness), helpless-hopeless (ie, the tendency to adopt a pessimistic attitude about the illness), anxious preoccupation (ie, the tendency to 
experience the illness as an event source of marked anxiety and tension) and cognitive avoidance (ie, the tendency to avoid direct confrontation with illnessrelated issues). We used the German version of the original MAC scale by Graul. ${ }^{34}$ Psychometric analyses showed sufficient results for all subscales in this study (Cronbach's $\alpha=0.67-0.84$ ) with the exception of the 'cognitive avoidance' scale (Cronbach's $\alpha=0.33$ ).

Regarding healthcare-related factors, patients were asked at follow-up if they had forgone any treatment because of financial barriers, waiting times or travel distance, to identify barriers of access to healthcare. ${ }^{35}$ Also at follow-up, patients were requested to indicate how many different healthcare services they had used, including possible radiotherapy or hormonal therapy after initial surgery (standard follow-up care, rehabilitation, complementary medicine, psychosocial care, self-help groups and/or ambulatory physiotherapy, with the response categories 'yes'/'no'). Quality of care was assessed by asking the patients, at baseline, about the quality of information they had been given about the diagnosis, disease, prognosis, course of disease, risks and side effects, treatment options and counselling. On a four-point Likert scale, the participants could rate these different aspects of care from 'very good' to 'poor'. A sum scale of the seven items was calculated (Cronbach's $\alpha=0.91$ ).

HRQOL was captured at baseline and follow-up by the established cancer-specific and multidimensional European Organisation for Research and Treatment of Cancer (EORTC) QLQ C-30 core questionnaire (V.3.0/ German translation), which includes 30 items (response categories: 'not at all'/'a little'/'quite a bit'/'very much'), with the exception of two items that evaluate the global quality of life ranging from (1) 'very poor' to (7) 'excellent'. ${ }^{36} 37$ Cronbach's $\alpha$ of this global quality of life scale was 0.86 at baseline and 0.94 at follow-up. Furthermore, five functional scales assess physical function (five items, Cronbach's $\alpha=0.73$ and 0.75 ), role function (two items, $\alpha=0.81$ and 0.81 ), emotional function (four items, $\alpha=0.86$ and 0.89), cognitive function (two items, $\alpha=0.74$ and 0.76 ) and social function (two items, $\alpha=0.79$ and 0.81 ). The symptom scales measure fatigue (three items, $\alpha=0.77$ and 0.88), pain (two items, $\alpha=0.91$ and 0.87 ), and nausea and vomiting (two items, $\alpha=0.21$ and 0.18). Moreover, single items assess dyspnoea, insomnia, appetite loss, constipation, diarrhoea and financial difficulties due to the disease. The scores range from 0 to 100 and a higher score represents a higher level of functioning as well as a greater degree of symptoms. At baseline, the patients were asked to estimate their quality of life in the week before hospital admission, at follow-up, this referred to the past week before questioning.

\section{Statistical analyses}

Descriptive statistics are reported for characteristics at baseline and follow-up. A paired t-test was applied to identify significant changes over time in the QLQ C-30 scales. To estimate the associations between SES and HRQOL in a longitudinal design, generalised estimating equations were calculated (correlation structure $\operatorname{AR}(1)$ ), which account for the within-participant correlation of outcomes. ${ }^{38}$ Standardised regression coefficients including $95 \%$ CIs are documented. First, the impact of each of the three SES indicators on HRQOL at follow-up was calculated adjusted for age and the respective subscale of HRQOL at baseline (basic model). Second, disease, patient and healthcare factors were introduced separately into the model to identify their single contribution. These analyses were conducted only in case of significance $(p<0.05)$ in the basic model. Finally, in the full model, all explanatory factors were introduced simultaneously. Patients who did not provide complete data for all included variables in the full model were excluded. All analyses were conducted with the statistical software IBM SPSS Statistics V.22.0.

\section{RESULTS}

The sample characteristics are shown in table 1 . The mean age at baseline was almost 58 years and about a half of the participants indicated the highest educational level; $20 \%$ were among the highest occupational group. Nearly one-third of participants were privately insured and the mean time between diagnosis and surgery was about 3.6 months. Regarding the disease factors, the majority of patients presented at a localised tumour stage while a quarter indicated an aggressive tumour, based on Gleason grading and about $18 \%$ had positive surgical margin status.

The scores of the QLQ C-30 scales at baseline and follow-up including the significance of change are reported in table 2. Notably, role function and symptoms of fatigue worsened during the observation time. Furthermore, physical and social function decreased, while emotional function improved. The scores regarding pain, dyspnoea, diarrhoea and financial difficulties significantly increased.

The standardised regression coefficients in tables 3 and 4 provide information about the associations between SES-separately calculated for income, education and occupational status-and the scales of HRQOL at follow-up.

In terms of the global quality of life scale and the functional scales (ie, physical, role, emotional, cognitive and social function), it becomes apparent that all scales are significantly associated with the inequality indicators in the basic model (table 3). Only cognitive function reveals barely significant associations. Patients with lower income, lower education and lower occupational status indicated less quality of life 6 months after radical prostatectomy, particularly in the case of physical and role function. The introduction of explanatory factors leads to moderate changes in inequalities in the full model. The majority of the initial associations remain significant 
Table 1 Sample characteristics at baseline $(n=246)$ and follow-up (if indicated; $n=233$ ): $n^{*}(\%)$ or mean $\pm S D$

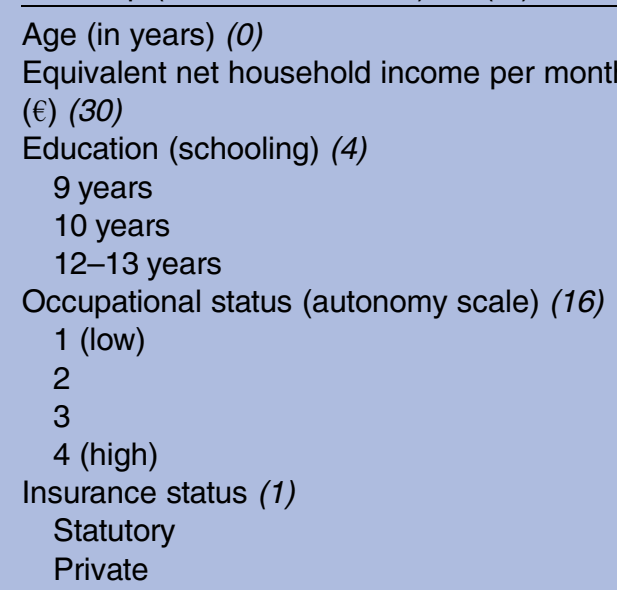

$(€)(30)$

(schooling) (4)

years

$57.6 \pm 5.1$

$2028 \pm 740$

$39(16.1)$

$74(30.6)$

$129(53.3)$

$40(17.4)$

$52(22.6)$

$92(40.0)$

$46(20.0)$

$158(64.5)$

$87(35.5)$

Time between diagnosis and surgery

(months) (8)

Tumour stage (UICC) (0)

$$
\text { III }
$$

IV

$3.59 \pm 4.47$

$20(8.1)$

$151(61.4)$

$46(18.7)$

$29(11.8)$

Tumour aggressivity (Gleason grade) (0) Less aggressive

Aggressive

$185(75.2)$

$61(24.8)$

Surgical margin status (1)

Negative

Positive

$200(81.6)$

$45(18.4)$

Comorbidity (number of chronic illnesses) (1)

0

1

$>2$

Coping (Mini-MAC) (scaled 1-4) (8)

Fatalism

$168(68.6)$

$45(18.4)$

$32(13.1)$

$2.83 \pm 0.53$

Fighting spirit

Helpless-hopeless

Anxious preoccupation

Cognitive avoidance

Social support (ISSS) (scaled 0-4)

Positive support (9)

Detrimental interaction (12)

$3.47 \pm 0.59$

$1.25 \pm 0.34$

$1.96 \pm 0.62$

$2.35 \pm 0.79$

$3.57 \pm 0.56$

$0.96 \pm 0.81$

Quality of informationt (scaled 0 (very good)

$0.64 \pm 0.63$

to 4 (poor)) (10)

Barriers of access $\ddagger$ (at follow-up) (4)

No

$217(94.8)$

$12(5.2)$

Healthcare use§ (at follow-up) (1-6) (18) $\quad 1.98 \pm 1.08$

${ }^{*}$ Amount of missing data in italics.

†nformation about diagnosis, disease, prognosis, course of

disease, risks and side effects, treatment options and counselling (sum scale).

†Financial barriers, waiting times or travel distance.

§Use of up to six healthcare services: standard follow-up care,

rehabilitation, complementary medicine, psychosocial care,

self-help groups and ambulatory physiotherapy.

ISSS, IIIness-Specific Social Support Scale; Mini-MAC,

Mini-Mental Adjustment to Cancer; UICC, Union for International Cancer Control.
Table 2 Health-related quality of life ${ }^{*}$ at baseline and follow-up (6 months): mean $\pm S D+(n=230)$

\begin{tabular}{lllr}
\hline & & & p \\
QLQ-C30-subscales & Baseline & Follow-up & \multicolumn{1}{c}{ Value } \\
\hline Global quality of life & $74.12 \pm 20.38$ & $73.65 \pm 19.10$ & 0.749 \\
Physical function & $97.13 \pm 8.32$ & $90.58 \pm 14.23$ & $<0.001$ \\
Role function & $92.25 \pm 17.00$ & $80.29 \pm 23.84$ & $<0.001$ \\
Emotional function & $67.75 \pm 25.24$ & $75.84 \pm 23.73$ & $<0.001$ \\
Cognitive function & $87.00 \pm 19.64$ & $84.50 \pm 20.79$ & 0.058 \\
Social function & $82.38 \pm 24.09$ & $78.07 \pm 25.26$ & 0.018 \\
Fatigue & $11.40 \pm 16.44$ & $22.13 \pm 22.92$ & $<0.001$ \\
Nausea and vomiting & $0.94 \pm 4.71$ & $1.74 \pm 6.56$ & 0.124 \\
Pain & $6.59 \pm 16.96$ & $11.81 \pm 19.25$ & $<0.001$ \\
Dyspnoea & $4.93 \pm 15.10$ & $11.59 \pm 22.05$ & $<0.001$ \\
Insomnia & $21.05 \pm 27.90$ & $21.64 \pm 27.80$ & 0.769 \\
Appetite loss & $4.97 \pm 16.10$ & $4.24 \pm 13.51$ & 0.493 \\
Constipation & $2.48 \pm 10.76$ & $3.64 \pm 11.32$ & 0.171 \\
Diarrhoea & $4.07 \pm 12.60$ & $7.28 \pm 16.38$ & 0.005 \\
Financial difficulties & $10.09 \pm 21.46$ & $13.45 \pm 24.53$ & 0.024 \\
\hline
\end{tabular}

${ }^{*}$ Scores range from 0 to 100 (a higher score represents a higher level of functioning and a greater degree of symptoms).

‡t-Test (paired).

after inclusion of disease, patient and healthcare factors. In particular cases, the associations between SES and global quality of life, cognitive and emotional function became insignificant. Associations are slightly more reduced by patient and healthcare factors than by disease factors. Moreover, income, education and occupational status have similar effects on differences in HRQOL concerning global quality of life and all functional scales.

In terms of the symptom scales, associations are less strong and consistent (table 4). Scales of fatigue, dyspnoea, diarrhoea and financial difficulties show significant associations with SES. There are no significant associations in the basic model regarding the remaining symptom scales. After introduction of explanatory variables, former significant associations (basic model) diminish in terms of fatigue, dyspnoea and diarrhoea when income is used as SES indicator. Associations are, rather, reduced by patient factors and healthcare factors. Among the symptom scales, occupational status does not play a relevant role.

\section{DISCUSSION}

The objective of this study was to identify associations between SES and HRQOL among patients with prostate cancer 6 months after radical prostatectomy, and, furthermore, contributory factors to explain any inequalities. Before introduction of the explanatory variables, the results indicate clear effects of SES on HRQOL particular in case of global quality of life and nearly all functional scales. Patients with lower income, education 


\begin{tabular}{|c|c|c|c|c|c|c|c|c|c|c|c|}
\hline \multirow[b]{2}{*}{ QLQ-C30-subscale } & \multirow[b]{2}{*}{ SES indicator } & \multicolumn{2}{|c|}{ Basic modelł } & \multicolumn{2}{|c|}{$\begin{array}{l}\text { Basic model+disease } \\
\text { factors }\end{array}$} & \multicolumn{2}{|c|}{$\begin{array}{l}\text { Basic model+patient } \\
\text { factors }\end{array}$} & \multicolumn{2}{|c|}{$\begin{array}{l}\text { Basic model } \\
\text { +healthcare factors }\end{array}$} & \multicolumn{2}{|c|}{$\begin{array}{l}\text { Full model (basic } \\
\text { model+all factors) }\end{array}$} \\
\hline & & $\overline{\mathbf{B}}$ & $95 \% \mathrm{Cl}$ & $\bar{\beta}$ & $95 \% \mathrm{Cl}$ & $\bar{\beta}$ & $95 \% \mathrm{Cl}$ & $\bar{\beta}$ & $95 \% \mathrm{Cl}$ & $\bar{\beta}$ & $95 \% \mathrm{Cl}$ \\
\hline \multirow[t]{3}{*}{ Global quality of life } & Income & $0.15^{\star}$ & 0.01 to 0.29 & $0.14^{\star}$ & 0.01 to 0.27 & 0.14 & 0.00 to 0.28 & 0.09 & -0.04 to 0.23 & 0.09 & -0.03 to 0.22 \\
\hline & Education & $0.12^{\star}$ & 0.01 to 0.23 & $0.12^{\star}$ & 0.01 to 0.23 & 0.11 & 0.00 to 0.21 & $0.13^{\star}$ & 0.03 to 0.24 & $0.12^{\star}$ & 0.01 to 0.23 \\
\hline & Occupation & $0.16^{\star *}$ & 0.05 to 0.28 & $0.17^{\star \star}$ & 0.06 to 0.28 & 0.10 & -0.01 to 0.21 & $0.14^{\star}$ & 0.03 to 0.25 & $0.11^{*}$ & 0.01 to 0.21 \\
\hline \multirow[t]{3}{*}{ Physical function } & Income & $0.19^{\star \star \star}$ & 0.10 to 0.29 & $0.16^{\star \star \star}$ & 0.08 to 0.25 & $0.18^{\star \star \star}$ & 0.09 to 0.28 & $0.18^{\star \star \star}$ & 0.08 to 0.28 & $0.15^{\star \star}$ & 0.06 to 0.24 \\
\hline & Education & $0.15^{\star \star}$ & 0.06 to 0.23 & $0.14^{\star \star}$ & 0.06 to 0.23 & $0.13^{\star \star}$ & 0.04 to 0.22 & $0.15^{\star \star}$ & 0.07 to 0.24 & $0.13^{\star *}$ & 0.04 to 0.22 \\
\hline & Occupation & $0.16^{\star \star \star}$ & 0.08 to 0.24 & $0.16^{\star \star \star}$ & 0.08 to 0.23 & $0.12^{\star \star}$ & 0.04 to 0.21 & $0.15^{\star \star \star}$ & 0.07 to 0.23 & $0.12^{\star *}$ & 0.04 to 0.21 \\
\hline \multirow[t]{3}{*}{ Role function } & Income & $0.28^{\star \star \star}$ & 0.16 to 0.40 & $0.27^{\star \star \star}$ & 0.15 to 0.39 & $0.28^{\star \star \star}$ & 0.16 to 0.40 & $0.26^{\star \star \star}$ & 0.15 to 0.38 & $0.27^{\star \star \star}$ & 0.15 to 0.38 \\
\hline & Education & $0.21^{\star \star \star}$ & 0.11 to 0.31 & $0.21^{\star \star \star}$ & 0.11 to 0.31 & $0.22^{\star \star \star}$ & 0.12 to 0.32 & $0.22^{\star \star \star}$ & 0.13 to 0.32 & $0.22^{\star \star \star}$ & 0.13 to 0.31 \\
\hline & Occupation & $0.21^{\star \star \star}$ & 0.13 to 0.29 & $0.21^{\star \star \star}$ & 0.13 to 0.29 & $0.18^{\star \star \star}$ & 0.10 to 0.27 & $0.19^{\star \star \star}$ & 0.11 to 0.27 & $0.18^{\star \star \star}$ & 0.10 to 0.26 \\
\hline \multirow[t]{3}{*}{ Emotional function } & Income & $0.13^{*}$ & 0.01 to 0.25 & 0.12 & -0.01 to 0.24 & $0.15^{\star}$ & 0.04 to 0.26 & 0.08 & -0.04 to 0.19 & $0.11^{*}$ & 0.01 to 0.21 \\
\hline & Education & 0.11 & -0.01 to 0.23 & - & - & - & - & - & - & - & - \\
\hline & Occupation & $0.14^{\star}$ & 0.02 to 0.26 & $0.15^{\star}$ & 0.03 to 0.26 & 0.06 & -0.03 to 0.16 & 0.11 & 0.00 to 0.23 & 0.05 & -0.04 to 0.14 \\
\hline \multirow[t]{3}{*}{ Cognitive function } & Income & 0.06 & -0.08 to 0.20 & - & - & - & - & - & - & - & - \\
\hline & Education & $0.13^{\star}$ & 0.02 to 0.25 & $0.13^{\star}$ & 0.02 to 0.24 & $0.11^{*}$ & 0.00 to 0.23 & $0.15^{\star}$ & 0.03 to 0.26 & 0.10 & -0.01 to 0.21 \\
\hline & Occupation & 0.07 & -0.06 to 0.20 & - & - & - & - & - & - & - & - \\
\hline \multirow[t]{3}{*}{ Social function } & Income & $0.17^{\star *}$ & 0.07 to 0.27 & $0.15^{\star \star}$ & 0.05 to 0.26 & $0.16^{\star *}$ & 0.06 to 0.26 & $0.15^{\star \star}$ & 0.06 to 0.24 & $0.13^{\star \star}$ & 0.04 to 0.23 \\
\hline & Education & $0.12^{\star}$ & 0.02 to 0.22 & $0.12^{*}$ & 0.02 to 0.22 & 0.09 & 0.00 to 0.19 & $0.15^{\star \star}$ & 0.06 to 0.25 & $0.11^{*}$ & 0.02 to 0.20 \\
\hline & Occupation & $0.18^{\star \star}$ & 0.06 to 0.30 & $0.18^{\star \star}$ & 0.07 to 0.30 & $0.12^{\star}$ & 0.01 to 0.23 & $0.17^{\star \star}$ & 0.06 to 0.28 & $0.12^{*}$ & 0.02 to 0.21 \\
\hline
\end{tabular}




\begin{tabular}{|c|c|c|c|c|c|c|c|c|c|c|c|}
\hline \multirow[b]{2}{*}{ QLQ-C30-subscale } & \multirow[b]{2}{*}{ SES indicator } & \multicolumn{2}{|c|}{ Basic modelł } & \multicolumn{2}{|c|}{$\begin{array}{l}\text { Basic model+disease } \\
\text { factors }\end{array}$} & \multicolumn{2}{|c|}{$\begin{array}{l}\text { Basic model+patient } \\
\text { factors }\end{array}$} & \multicolumn{2}{|c|}{$\begin{array}{l}\text { Basic model+healthcare } \\
\text { factors }\end{array}$} & \multicolumn{2}{|c|}{$\begin{array}{l}\text { Full model (basic } \\
\text { model+all factors) }\end{array}$} \\
\hline & & $\boldsymbol{\beta}$ & $95 \% \mathrm{Cl}$ & $\boldsymbol{\beta}$ & $95 \% \mathrm{Cl}$ & $\boldsymbol{\beta}$ & $95 \% \mathrm{Cl}$ & $\bar{\beta}$ & $95 \% \mathrm{Cl}$ & $\boldsymbol{\beta}$ & $95 \% \mathrm{Cl}$ \\
\hline \multirow[t]{3}{*}{ Fatigue } & Income & $-0.13^{\star}$ & -0.26 to -0.01 & -0.12 & -0.24 to 0.00 & -0.10 & -0.22 to 0.02 & -0.10 & -0.23 to -0.04 & -0.07 & -0.18 to 0.04 \\
\hline & Education & $-0.13^{\star}$ & -0.24 to -0.02 & $-0.13^{\star}$ & -0.24 to -0.03 & $-0.10^{\star}$ & -0.20 to -0.01 & $-0.15^{\star}$ & -0.26 to -0.03 & $-0.11^{\star}$ & -0.20 to -0.01 \\
\hline & Occupation & -0.11 & -0.23 to 0.00 & - & - & - & - & - & - & - & - \\
\hline \multirow[t]{3}{*}{ Nausea and vomiting } & Income & -0.06 & -0.13 to 0.02 & - & - & - & - & - & - & - & - \\
\hline & Education & -0.01 & -0.10 to 0.08 & - & - & - & - & - & - & - & - \\
\hline & Occupation & -0.04 & -0.12 to 0.05 & - & - & - & - & - & - & - & - \\
\hline \multirow[t]{3}{*}{ Pain } & Income & -0.09 & -0.21 to 0.02 & - & - & - & - & - & - & - & - \\
\hline & Education & -0.05 & -0.15 to 0.06 & - & - & - & - & - & - & - & - \\
\hline & Occupation & -0.09 & -0.19 to 0.00 & - & - & - & - & - & - & - & - \\
\hline \multirow[t]{3}{*}{ Dyspnoea } & Income & $-0.14^{\star}$ & -0.27 to -0.01 & $-0.13^{\star}$ & -0.26 to -0.01 & -0.12 & -0.25 to 0.01 & -0.08 & -0.21 to 0.04 & -0.09 & -0.20 to 0.03 \\
\hline & Education & $-0.15^{\star}$ & -0.29 to -0.01 & $-0.15^{\star}$ & -0.30 to -0.01 & $-0.14^{\star}$ & -0.27 to -0.02 & $-0.14^{\star}$ & -0.28 to -0.01 & $-0.14^{\star}$ & -0.26 to -0.02 \\
\hline & Occupation & -0.05 & -0.15 to 0.05 & - & - & - & - & - & - & - & - \\
\hline \multirow[t]{3}{*}{ Insomnia } & Income & -0.08 & -0.20 to 0.03 & - & - & - & - & - & - & - & - \\
\hline & Education & -0.06 & -0.17 to 0.05 & - & - & - & - & - & - & - & - \\
\hline & Occupation & -0.06 & -0.19 to 0.06 & - & - & - & - & - & - & - & - \\
\hline \multirow[t]{3}{*}{ Appetite loss } & Income & -0.06 & -0.18 to 0.06 & - & - & - & - & - & - & - & - \\
\hline & Education & -0.06 & -0.19 to 0.07 & - & - & - & - & - & - & - & - \\
\hline & Occupation & -0.05 & -0.14 to 0.04 & - & - & - & - & - & - & - & - \\
\hline \multirow[t]{3}{*}{ Constipation } & Income & -0.01 & -0.13 to 0.11 & - & - & - & - & - & - & - & - \\
\hline & Education & -0.11 & -0.26 to 0.04 & - & - & - & - & - & - & - & - \\
\hline & Occupation & -0.05 & -0.18 to 0.08 & - & - & - & - & - & - & - & - \\
\hline \multirow[t]{3}{*}{ Diarrhoea } & Income & $-0.15^{\star}$ & -0.28 to -0.02 & $-0.12^{\star}$ & -0.24 to -0.01 & -0.10 & -0.23 to 0.02 & $-0.14^{\star}$ & -0.27 to -0.01 & -0.07 & -0.18 to 0.04 \\
\hline & Education & -0.06 & -0.16 to 0.05 & - & - & - & - & - & - & - & - \\
\hline & Occupation & -0.03 & -0.13 to 0.07 & - & - & - & - & - & - & & - \\
\hline \multirow[t]{3}{*}{ Financial difficulties } & Income & $-0.25^{\star \star *}$ & -0.37 to -0.17 & $-0.23^{\star \star *}$ & -0.35 to -0.11 & $-0.25^{\star \star \star}$ & -0.39 to -0.12 & $-0.21^{\star \star}$ & -0.33 to -0.09 & $-0.19^{\star \star}$ & -0.33 to -0.05 \\
\hline & Education & $-0.20^{\star \star}$ & -0.32 to -0.07 & $-0.20^{\star \star}$ & -0.31 to -0.08 & $-0.17^{\star}$ & -0.30 to -0.04 & $-0.19^{\star *}$ & -0.32 to -0.06 & $-0.17^{\star}$ & -0.30 to -0.04 \\
\hline & Occupation & $-0.17^{\star \star}$ & -0.26 to -0.07 & $-0.17^{\star \star \star}$ & -0.27 to 0.08 & $-0.14^{\star}$ & -0.24 to -0.03 & $-0.14^{\star \star}$ & -0.24 to -0.04 & $-0.14^{\star}$ & -0.24 to -0.03 \\
\hline $\begin{array}{l}\text { Basic model: SES (incom } \\
\text { Disease factors: tumour } \\
\text { Patient factors: comorbidi } \\
\text { Healthcare factors: barrie } \\
\text { †Values in bold are signif } \\
\text { †Further analysis was cor }\end{array}$ & $\begin{array}{l}\text { ne OR education C } \\
\text { stage, Gleason scc } \\
\text { ity, coping, social } \\
\text { ers of access, num } \\
\text { ficant }\left({ }^{*} p<0.05 ;{ }^{* *} p\right. \\
\text { nducted only wher }\end{array}$ & $\begin{array}{l}\text { R occupati } \\
\text { ore, surgical } \\
\text { support. } \\
\text { ber of utilisa } \\
D<0.01 ;{ }^{* \star *} p \\
\beta \beta \text { was stat }\end{array}$ & $\begin{array}{l}\text { on), age. } \\
\text { I margin status. } \\
\text { ations, perceived qu } \\
<0.001 ; \text { Wald- } \chi^{2} \text { te } \\
\text { istically significant }\end{array}$ & $\begin{array}{l}\text { uality of infor } \\
\text { st). } \\
(p<0.05) \text { in }\end{array}$ & $\begin{array}{l}\text { rmation. } \\
\text { basic model. }\end{array}$ & & & & & & \\
\hline
\end{tabular}


or occupational status reported a lower quality of life. After inclusion of the disease-related, patient-related and healthcare-related factors-associations are slightly reduced and remain significant in the majority of cases. In particular, physical and role functions still indicate strong associations with SES. In some cases, associations become insignificant and social differences no longer exist. The symptom scales are marginally associated with SES. Patient factors (comorbidity and psychosocial factors such as coping strategies and social support) and in some instances healthcare factors (barriers of access, healthcare use, quality of information) tend to contribute to social inequalities in HRQOL rather than those that are disease related (tumour stadium, Gleason grade, surgical margin status).

Owing to methodical diversity, comparisons with other studies' results are difficult. Two cross-sectional studies showed associations between lower SES and lower scores of quality of life among patients with prostate cancer. ${ }^{15} 19$ The only study to analyse social inequalities for long-term prostate cancer survivors revealed persisting differences indicating lower mental HRQOL among patients with low SES. ${ }^{16}$ The existing prospective studies usually reported social inequalities at baseline and a diminishing trend at follow-ups, although observation times vary. ${ }^{14} 18 \quad 2021$ One study, restricted to a lowincome sample, did not find significant changes among patients with educational inequalities 6 months after baseline survey. ${ }^{17}$ The present study shows disparities, 6 months after treatment, regarding global quality of life and various functional and symptom scales or items.

Two German papers showed that, among other factors, SES predicts lower HRQOL (based on the QLQ C-30) about 12-16 months after diagnosis or treatment. ${ }^{39}{ }^{40}$ However, in one case, the analysis was limited to the global quality of life scale and the associations diminished after 2 more years, and in the other case, comparisons with population-based normative data were conducted only indicating significant associations with physical function. Concerning the explanatory factors, studies reported that factors such as stage, comorbidity, social support and healthcare, were associated with social disparities among patients with cancer. ${ }^{25} 272841$ The analyses of explanatory factors in the present study show only moderate effects on the association between SES and HRQOL. Disease-related, patient-related and healthcare-related factors lead to reductions of the coefficients only in some cases. In terms of three-symptom scales, the significance disappears in the full model when considering income. Patient factors such as comorbidity or psychosocial conditions and, partly, healthcare factors, seem to be more important in explaining the inequalities than disease-related factors. The aforementioned Dutch study analysing long-term survivors showed similar findings. ${ }^{16}$ Although the evidence base is currently underdeveloped, the relevance of social support and coping strategies for HRQOL among patients with prostate cancer was shown in different studies. ${ }^{42}$ Concerning healthcare, differences in prostate cancer treatment options (ie, alternatives to surgery) could also have a major effect on HRQOL disparities $^{43} 44$ and on the associations with SES. ${ }^{45} 46$ However, as all participants in the present study underwent the same kind of treatment at baseline, this common explanation could not be investigated.

Some methodological aspects need to be discussed when interpreting the findings. The prospective design of the study allows drawing conclusions about causalities with regard to the observation time. Generalised estimating equations are suitable to analyse associations in longitudinal data. The response rates at baseline and follow-up are very satisfying, but the study population is selective and therefore not representative of the basic population of treated patients with prostate cancer in Germany. Although there was no detailed information about the educational distribution among the basic population, the study population consists of many comparatively well-educated participants. This may be due to the hospitals included in this study. Although both privately insured patients and statutory insured patients have access to the clinics, hospital statistics show that the percentage of patients with private insurance is comparatively large. Thus, our findings might underestimate the degree of social inequality in HRQOL among patients with prostate cancer. However, in the present study, patients older than 65 years were excluded, which also might result in a higher proportion of well-educated patients in the sample. Moreover, higher incidence rates of patients with prostate cancer with higher SES were shown in multiple Western countries. ${ }^{47-50}$ Furthermore, the inclusion of numerous explanatory variables represents a broad spectrum of factors but increases the number of missing cases. Depending on the respective SES indicator, 166-186 of the 233 cases remain for the regression analyses. On the other hand, an analysis of missing values indicates only marginal differences between the means and percentage distributions of the complete data and the data used in the final regression analyses (not shown in detail). The QLQ C-30 is an established instrument for assessing HRQOL among patients with cancer, ${ }^{37}{ }^{51}$ and was tested successfully for its validity among patients with prostate cancer. ${ }^{12}$ Our analyses reveal a satisfactory reliability of the instrument's scales in our study (Cronbach's $\alpha$ from 0.73 to 0.94 ), with the exception of the nausea/vomiting scale. A further limitation is the crude analyses of explanatory factors. A more detailed mediation analysis that distinguishes between the concepts of confounding and mediation, and examines direct, indirect and total effects, would lead to a more precise interpretation. ${ }^{52} 53$ The present analysis followed a theory-driven approach using literature-based models for explanation. ${ }^{622} 23$ In this context, we simultaneously introduced multiple disease, patient or healthcare factors which would make a detailed mediation analysis difficult. 
To the best of our knowledge, this is one of the first studies to systematically analyse the effect of different SES indicators on multiple dimensions of HRQOL 6 months after surgery, especially in a European healthcare setting. Cross-sectional analyses of our data (results not shown) indicate only weak associations between SES and the QLQ C-30 subscales at baseline. By calculating generalised estimating equations, we took into account differences in HRQOL at baseline when analysing inequalities at follow-up. The results suggest that social inequalities increase during the observation time. Although some reductions in disparities could be observed after introduction of potential explanatory factors, a considerable number of inequalities remains significant. Thus, further potential factors have to be considered for explanation. Frederiksen $e t a t^{22}$ assumed, in their study among patients with colorectal cancer, that more indefinable and immeasurable factors could have played a role. Thus, people with low SES have a 'little less of everything' regarding a life course perspective. Moreover, they took into account the fact that measures of disease, patient or healthcare factors could have been rather crude and not able to reflect the multifaceted and differentiated conditions.

Other possible explanations refer to social determinants of health characterised by the circumstances in which people are born, grow, live, work and age. ${ }^{45}$ As health inequalities result from social inequalities, action across all social determinants of health is necessary. This refers to daily living conditions over the life course, for example, equity in early life, labour market disadvantage, psychosocial environment at work, social integration and material deprivation regarding housing, neighbourhoods, healthy environments and access to healthcare or prevention programmes. When addressing health equities, there is a tendency in public health to focus more on individual behaviour and less on the environmental drivers of these behaviours. In this regard, not only should the most disadvantaged be considered, but so should the whole social gradient in health and quality of life.

Finally, the findings show that, even in healthcare systems with obligatory health insurance and equal access, health inequalities persist. In our study of social disparities in HRQOL among patients with prostate cancer, evidence about the underlying causes is sparse and future research should focus on the identification of these causes.

\section{Twitter Follow Daniel Lüdecke at @strengejacke}

Acknowledgements The authors would like to thank the physicians, nurses and administrators of both participating hospitals for their support.

Furthermore, they would like to thank all participating patients.

Contributors JK, KH-G and OvdK designed the study. JK collected and prepared the data, drafted the manuscript, and analysed and interpreted the data. OvdK led the project and made an essential contribution to drafting the manuscript and interpreting the data. KH-G contributed to data preparation, and critically revised and approved the final manuscript. DL substantially contributed to data analyses and interpretation. MF and MG provided access to the study population, and critically revised and approved the final manuscript.

Funding This work was supported by the vffr (association for promotion of research in rehabilitation in Hamburg, Schleswig-Holstein and Mecklenburg-West Pomerania e V; grant number 172).

Competing interests None declared.

Ethics approval Ethics Committee Hamburg (PV4493).

Provenance and peer review Not commissioned; externally peer reviewed.

Data sharing statement No additional data are available.

Open Access This is an Open Access article distributed in accordance with the Creative Commons Attribution Non Commercial (CC BY-NC 4.0) license, which permits others to distribute, remix, adapt, build upon this work noncommercially, and license their derivative works on different terms, provided the original work is properly cited and the use is non-commercial. See: http:// creativecommons.org/licenses/by-nc/4.0/

\section{REFERENCES}

1. Mackenbach JP, Stirbu I, Roskam AJ, et al. Socioeconomic inequalities in health in 22 European countries. $N$ Engl J Med 2008;358:2468-81.

2. Mackenbach JP. The persistence of health inequalities in modern welfare states: the explanation of a paradox. Soc Sci Med 2012;75:761-9.

3. Glymour MM, Avendano M, Kawachi I. Socioeconomic status and health. In: Berkman LF, Kawachi I, Glymour MM, eds. Social epidemiology. New York: Oxford University Press, 2014:17-62.

4. Marmot M, Allen J, Bell R, et al. WHO European review of social determinants of health and the health divide. Lancet 2012;380:1011-29.

5. Klein J, von dem Knesebeck $\mathrm{O}$. Socioeconomic inequalities in prostate cancer survival: a review of the evidence and explanatory factors. Soc Sci Med 2015;142:9-18.

6. Woods LM, Rachet B, Coleman MP. Origins of socio-economic inequalities in cancer survival: a review. Ann Oncol 2006;17:5-19.

7. Montazeri A. Quality of life data as prognostic indicators of survival in cancer patients: an overview of the literature from 1982 to 2008. Health Qual Life Outcomes 2009;7:102.

8. Quinten C, Martinelli F, Coens C, et al. A global analysis of multitrial data investigating quality of life and symptoms as prognostic factors for survival in different tumor sites. Cancer 2014;120:302-11.

9. Penson DF, Litwin MS, Aaronson NK. Health related quality of life in men with prostate cancer. J Urol 2003;169:1653-61.

10. Sanson-Fisher R, Bailey LJ, Aranda S, et al. Quality of life research: is there a difference in output between the major cancer types? Eur J Cancer Care 2010;19:714-20.

11. Eton DT, Lepore SJ. Prostate cancer and health-related quality of life: a review of the literature. Psychooncology 2002;11:307-26.

12. Hamoen EHJ, De Rooij M, Witjes JA, et al. Measuring health-related quality of life in men with prostate cancer: a systematic review of the most used questionnaires and their validity. Urol Oncol 2015;33:69. e19-28.

13. Ramsey SD, Zeliadt SB, Hall IJ, et al. On the importance of race, socioeconomic status and comorbidity when evaluating quality of life in men with prostate cancer. J Urol 2007;177:1992-9.

14. Penson DF, Stoddard ML, Pasta DJ, et al. The association between socioeconomic status, health insurance coverage, and quality of life in men with prostate cancer. J Clin Epidemiol 2001;54:350-8.

15. Karakiewicz PI, Bhojani N, Neugut A, et al. The effect of comorbidity and socioeconomic status on sexual and urinary function and on general health-related quality of life in men treated with radical prostatectomy for localized prostate cancer. J Sex Med 2008;5:919-27.

16. Aarts MJ, Mols F, Thong MSY, et al. Long-term prostate cancer survivors with low socioeconomic status reported worse mental health-related quality of life in a population-based study. Urology 2010;76:1224-30

17. Augustus JS, Kwan L, Fink A, et al. Education as a predictor of quality of life outcomes among disadvantaged men. Prostate Cancer Prostatic Dis 2009;12:253-8.

18. Brar R, Maliski SL, Kwan L, et al. Changes in quality of life among low-income men treated for prostate cancer. Urology 2005;66:344-9. 
19. Krupski TL, Fink A, Kwan L, et al. Health-related quality-of-life in low-income, uninsured men with prostate cancer. J Health Care Poor Underserved 2005;16:375-90.

20. Simon AE, Wardle J. Socioeconomic disparities in psychosocial wellbeing in cancer patients. Eur J Cancer 2008;44:572-8.

21. Barbareschi G, Sanderman R, Tuinstra J, et al. A prospective study on educational level and adaptation to cancer, within one year after the diagnosis, in an older population. Psychooncology 2008;17:373-82.

22. Frederiksen $\mathrm{BL}$, Osler $\mathrm{M}$, Harling $\mathrm{H}$, et al. Do patient characteristics, disease, or treatment explain social inequality in survival from colorectal cancer? Soc Sci Med 2009;69:1107-15.

23. Auvinen A, Karjalainen S. Possible explanations for social class differences in cancer patient survival. In: Kogevinas M, Pearce N, Susser M, Bofetta $P$, eds. Social inequalities and cancer. Lyon: IARC Sci Publ, 1997:377-97.

24. Clegg LX, Reichman ME, Miller BA, et al. Impact of socioeconomic status on cancer incidence and stage at diagnosis: selected findings from the surveillance, epidemiology, and end results: National Longitudinal Mortality Study. Cancer Causes Control 2009;20:417-35.

25. Lyratzopoulos $\mathrm{G}$, Abel GA, Brown $\mathrm{CH}$, et al. Socio-demographic inequalities in stage of cancer diagnosis: evidence from patients with female breast, lung, colon, rectal, prostate, renal, bladder, melanoma, ovarian and endometrial cancer. Ann Oncol 2013;24:843-50.

26. Aarts MJ, Kamphuis CBM, Louwman MJ, et al. Educational inequalities in cancer survival: a role for comorbidities and health behaviours? J Epidemiol Community Health 2013;67:365-73.

27. Louwman WJ, Aarts MJ, Houterman S, et al. A $50 \%$ higher prevalence of life-shortening chronic conditions among cancer patients with low socioeconomic status. $\mathrm{Br} \mathrm{J}$ Cancer 2010;103:1742-8.

28. Harvei S, Kravdal O. The importance of marital and socioeconomic status in incidence and survival of prostate cancer. An analysis of complete Norwegian birth cohorts. Prev Med 1997;26: 623-32.

29. Lyratzopoulos G, Barbiere JM, Greenberg DC, et al. Population based time trends and socioeconomic variation in use of radiotherapy and radical surgery for prostate cancer in a UK region: continuous survey. BMJ 2010;340:c1928.

30. Williams N, Hughes LJ, Turner EL, et al. Prostate-specific antigen testing rates remain low in UK general practice: a cross-sectional study in six English cities. BJU Int 2011;108:1402-8.

31. Hoffmeyer-Zlotnik JHP. "Stellung im Beruf" als Ersatz für eine Berufsklassifikation zur Ermittlung von sozialem Prestige. Zuma Nachrichten 2003;53:114-27.

32. Watson M, Law MG, Santos M dos, et al. The Mini-MAC: further development of the Mental Adjustment to Cancer Scale. $J$ Psychosoc Oncol 1994:12:33-46.

33. Ullrich A, Mehnert A. [Psychometric validation of the 8-Item short-version of the Illness-specific Social Support Scale (ISSS) among cancer patients]. Klin Diagn Eval 2010;3:359-81.

34. Graul J. Krankheitsbewältigung und Lebensqualität bei Patienten mit gastrointestinen Tumoren unter Berücksichtigung psychosozialer Betreuung [Dissertation]. Hamburg, 1994.

35. Allin S, Grignon M, Le Grand J. Subjective unmet need and utilization of health care services in Canada: what are the equity implications? Soc Sci Med 2010;70:465-72.
36. Aaronson NK, Ahmedzai S, Bergman B, et al. The European Organization for Research and Treatment of Cancer QLQ-C30: a quality-of-life instrument for use in international clinical trials in oncology. J Natl Cancer Inst 1993;85:365-76.

37. Fayers P, Bottomley A. Quality of life research within the EORTCthe EORTC QLQ-C30. Eur J Cancer 2002;38(Suppl 4):S125-33.

38. Van Belle G, Fisher LD, Heagerty PJ, et al. Biostatistics: a methodology for the health sciences. 2nd edn. Hoboken, New Jersey: John Wiley \& Sons, Inc., 2004:728-65.

39. Perl M, Waldmann A, Pritzkuleit R, et al. [Temporal changes in quality of life after prostate carcinoma]. Urologe A 2012;51:706-12.

40. Henninger S, Neusser S, Lorenz C, et al. [Prostate cancer in routine healthcare: health-related quality of life after inpatient treatment]. Urologe A 2014;53:1793-9.

41. Rapiti E, Fioretta G, Schaffar R, et al. Impact of socioeconomic status on prostate cancer diagnosis, treatment, and prognosis. Cancer 2009;115:5556-65.

42. Paterson C, Jones M, Rattray J, et al. Exploring the relationship between coping, social support and health-related quality of life for prostate cancer survivors: a review of the literature. Eur J Oncol Nurs 2013;17:750-9.

43. Gomella LG, Johannes J, Trabulsi EJ. Current prostate cancer treatments: effect on quality of life. Urology 2009;73(Suppl 5): S28-35.

44. Smith DP, King MT, Egger S, et al. Quality of life three years after diagnosis of localised prostate cancer: population based cohort study. BMJ 2009;339:b4817.

45. Schwartz K, Powell IJ, Underwood W III, et al. Interplay of race, socioeconomic status, and treatment on survival of patients with prostate cancer. Urology 2009;74:1296-302.

46. Aarts MJ, Koldewijn EL, Poortmans PM, et al. The impact of socioeconomic status on prostate cancer treatment and survival in the Southern Netherlands. Urology 2013;81:593-9.

47. Hastert TA, Beresford SAA, Sheppard L, et al. Disparities in cancer incidence and mortality by area-level socioeconomic status: a multilevel analysis. J Epidemiol Community Health 2015;69:168-76.

48. Shafique $K$, Oliphant R, Morrison DS. The impact of socio-economic circumstances on overall and grade-specific prostate cancer incidence: a population-based study. Br J Cancer 2012;107: 575-82.

49. Eberle A, Luttmann S, Foraita R, et al. Socioeconomic inequalities in cancer incidence and mortality - a spatial analysis in Bremen, Germany. J Public Health 2010;18:227-35.

50. Marså K, Johnsen NF, Bidstrup PE, et al. Social inequality and incidence of and survival from male genital cancer in a population-based study in Denmark, 1994-2003. Eur J Cancer 2008;44:2018-29.

51. Velikova G, Coens C, Efficace F, et al. Health-related quality of life in EORTC clinical trials -30 years of progress from methodological developments to making a real impact on oncology practice. Eur $J$ Cancer Supp/ 2012;10:141-9.

52. Valeri L, Vanderweele TJ. Mediation analysis allowing for exposure-mediator interactions and causal interpretation: theoretical assumptions and implementation with SAS and SPSS macros. Psychol Methods 2013;18:137-50.

53. VanderWeele TJ. Mediation and mechanism. Eur J Epidemiol 2009;24:217-24.

54. Marmot M. Fair society, healthy lives: strategic review of health inequalities in England post 2010. London: Marmot Review, 2010. 